\title{
DESIGN HÍBRIDO: caminhos, processos e transformações
}

\author{
Tatiana Azzi Roizenbruch \\ UEMG - Universidade do Estado de Minas Gerais \\ tatiazzi@gmail.com
}

\begin{abstract}
RESUMO
Este artigo é uma reflexão sobre algumas das questões que envolvem o design hoje no Brasil. Entender as relações e os caminhos encontrados pelo design contemporâneo é uma forma de compreender como existem diversas possibilidades projetuais, além daquelas inicialmente conhecidas pelo design. Questões culturais e sociais estão cada vez mais presentes nestes contatos e o design no Brasil está repleto de novas e boas possibilidades. Através do conceito de hibridismo, o artigo mostra de que forma as misturas entre diferentes áreas da cultura favorecem o design e como a troca de saberes e o respeito a multiculturalidade são novas características para as produções locais. Percebemos o design em constante renovação, mais livre e mais expressivo, dentro deste novo cenário mundial.
\end{abstract}

Palavras-chave: Design. Hibridismo. Multiculturalismo. Cultura Material.

\section{ABSTRACT}

This article is a reflection of some of the issues surrounding the design in Brazil today. To understand relationships and the paths found by contemporary design is a way to understand how exist several projective possibilities, beyond those already known by design. Cultural and social issues are presents in those contacts and the design in Brazil is full of new possibilities. Through the concept of hybridity, the paper shows how mixtures of different areas of culture supports the design and how the exchange of knowledge and respect for multiculturalism are the new features for local productions. We realized the design in constant renovation, freer and more expressive, within this new global world.

Keywords: Design. Hybridity. Multiculturalism. Material Culture.

\section{INTRODUÇÃO}

Amálio Pinheiro, em uma palestra em 2007, questionou qual seria a identidade do Brasil e concluiu dizendo que não havia como definir uma identidade brasileira, pois o país é formado de fragmentos vindos de várias partes do mundo "o Brasil é repleto 
de assimetrias e descontinuidades, tudo o que fazemos contém elementos vindos de várias civilizações, sem que sejamos nenhuma delas", disse.

Somos uma montagem de fragmentos descontínuos, como um mosaico. Aliás, o mosaico é a imagem utilizada por Pinheiro para caracterizar o Brasil. Como achamos a imagem muito interessante, decidimos utilizá-la também neste artigo, pois o mosaico é formado por diversos fragmentos descontínuos, assim como os diversos povos que formam a cultura mestiça do país.

Amálio Pinheiro falou ainda sobre os dois tipos de cultura existentes: aquelas que tendem à simplificação, tornando-se inteligíveis; e outras que estão em contínua mutação, são plurais, polifônicas e, como ele bem disse, difíceis de entender. Nesta última idéia, encaixamos a cultura brasileira, mestiça, plural, híbrida: "não há modo de produzir pensamento sem relacionar com a cultura", completou Pinheiro. E é através dessa imagem que conduziremos o artigo a seguir.

\section{DESENVOLVIMENTO}

\subsection{CULTURA E CULTURA MATERIAL}

Existem diversas abordagens sobre o conceito de cultura. Segundo a abordagem de Geertz (1989) e sua visão interpretativista, a cultura seria como uma teia de significados tecida pelas pessoas na sociedade; nela, as pessoas desenvolvem seus pensamentos, valores e ações; e a partir dela, as pessoas interpretam o significado de sua própria existência. De acordo com Canclini (1983), a cultura é um fenômeno capaz de representar, reproduzir e transformar os elementos que conformam o sistema social e a vida, influenciando e sendo influenciada pelas práticas econômicas e relações simbólicas.

Existe então a necessidade de interação entre diferentes áreas da cultura, para que todas as promoções, sejam estéticas, simbólicas ou tecnológicas, estejam em sintonia com as demandas das pessoas dessa cultura.

Cultura é vista como um conjunto de símbolos significantes, um código, um mapa mental ou uma linguagem que fornece a orientação e as referências necessárias para que as pessoas possam viver em grupo. Nesse sentido, não se pode dizer que existam povos sem cultura, porque todos eles possuem regras e significados de como as coisas são ou como devem ser. A concepção, produção e uso de objetos também possuem suas referencias que compõem a cultura de cada grupo. Eles estão, portanto, impregnados de cultura. (Carvalho in Ono, 2006: XI).

Partindo desses conceitos iniciais de cultura, percebemos que ela é formada pela expressão artística, política e espiritual de uma sociedade. A cultura de um povo é formada por aquilo que é produzido pelos seus membros: "bens e valores que, através das coordenadas de tempo e espaço, caracterizam as identidades de seus membros" (Cipiniuk; Portinari; Bomfim, 2008:61). Essa cultura, particularizada nos objetos gerados por essas expressões, é chamada de cultura material. Esses objetos, produzidos pelo trabalho humano, são caracterizados como artefato.

Generalizando a partir do artefato individual para o conjunto de artefatos produzidos e usados por um determinado grupo ou por uma determinada sociedade, chegamos ao conceito de cultura material, termo que tem a sua origem na etnologia e 
no estudo dos artefatos de povos considerados 'primitivos' pelos seus colonizadores europeus. Hoje, porém, esse conceito ganhou uma dimensão mais ampla e podemos falar da cultura material da nossa própria sociedade como uma maneira de entender melhor os artefatos que produzimos e consumimos, bem como a maneira em que estes se encaixam em sistemas simbólicos e ideológicos mais amplos (Cardoso, 1998:19).

O termo 'cultura material' foi muito usado no século XIX por arqueólogos, etnólogos e antropólogos. A partir desse período, verificou-se que o estudo desse conceito poderia ajudar a esclarecer algumas questões. O conceito abrangente de cultura material já foi entendido como conjunto da então arte produzida pelos povos primitivos - do latim, arte factus. O que entendemos hoje por artefato refere-se aos objetos produzidos pelo trabalho humano e se contrapõe, portanto, aos objetos naturais ou acidentais. Trata-se de uma categoria muito ampla, abrangendo sem distinção objetos tecnológicos e artísticos, industriais e artesanais, independentemente de função, utilidade ou valor simbólico (Cardoso, 2008:21).

Essa noção de artefato é então definidora da noção de cultura material explicitada aqui.

Se pensarmos que, independente da função ou forma dos objetos, eles são vistos como artefatos, pois são frutos da produção humana, podemos pensar o design como área geradora de artefatos também. Assim, fica claro que o design é parte da cultura material de um povo, da mesma forma que é, também, parte da cultura de uma forma geral.

A relação entre design, cultura e sociedade pode ser observada a partir da própria experiência empírica. Primeiro porque design é uma atividade que configura objetos de uso e sistemas de informação e, como tal, incorpora parte dos valores culturais que a cerca, ou seja, a maioria dos objetos de nosso meio é, antes de tudo, a materialização dos ideais e das incoerências de nossas sociedades e de suas manifestações culturais, assim como, por outro lado, anúncio de novos caminhos. Segundo, porque o design, entendido como matéria (ou energia) conformada participa da criação cultural, ou seja, o design é uma práxis que confirma ou questiona a cultura de uma determinada sociedade, o que caracteriza um processo dialético entre mimese e poese. Em outras palavras, o design tem assim natureza essencialmente especular, quer como anúncio, quer como denúncia (Cipiniuk; Portinari; Bomfim, 2008:61).

Os objetos produzidos pelas sociedades passam a ser uma extensão da mesma, pois são fruto de quem os criou, como vimos. Assim, o conjunto desses objetos pode caracterizar a identidade dos povos, não só por suas características de forma, função ou matéria-prima, mas principalmente pela função que exercem dentro da sociedade. $\mathrm{Na}$ tentativa de homogeneização das sociedades, elementos caracterizadores das identidades culturais de um determinado povo podem ser transformados, adquirindo novas características, à medida que se propagam de região para região. A identidade cultural é então fruto dessa produção material, e conseqüentemente, do design. Nas palavras de Cardoso (1998:22), o design constitui, grosso modo, a fonte mais importante da maior parte da cultura material de uma sociedade que, mais do que qualquer outra sociedade que já existiu, pauta a sua identidade cultural na abundância material que tem conseguido gerar. 


\subsection{AS TROCAS CULTURAIS}

Todos os povos estão impregnados de cultura, mas, como percebemos, o Brasil e outros países periféricos formam a cultura mestiça, onde diversas outras culturas estão presentes, o que altera a percepção de uma "identidade" cultural.

De acordo com Ana Mae Barbosa (1998:14), "a identidade cultural não é uma forma fixa ou congelada, mas um processo dinâmico, enriquecido através do diálogo e trocas com as outras culturas". Daí a necessidade das trocas culturais - e não só entre países, mas também dentro de um mesmo país, principalmente no caso de países com identidades plurais, como o Brasil. O reconhecimento de códigos culturais entre diferentes classes e grupos étnicos, bem como entre sexos, religiões e crenças, é também necessário para o reconhecimento da diversidade cultural e sua assimilação.

Todas as classes tem o direito de acesso aos códigos da cultura erudita porque esses são os códigos dominantes - os códigos do poder. É necessário conhecê-los, ser versado neles, mas tais códigos continuarão a ser um conhecimento exterior a não ser que o indivíduo tenha dominado as referências culturais da própria classe social, a porta de entrada para assimilação do 'outro. A mobilidade social depende da interrelação entre os códigos culturais das diferentes classes sociais (Barbosa, 1998:15).

Peter Burke afirma a necessidade das trocas culturais para o crescimento da cultura, quando diz: "de qualquer forma, acho convincente o argumento de que toda inovação é uma espécie de adaptação e que encontros culturais encorajam a criatividade" (Burke, 2003:17). Essas trocas culturais podem ser entendidas também como uma forma de interculturalidade: "enquanto os termos "multicultural" e "pluricultural" significam a coexistência e mútuo entendimento de diferentes culturas na mesma sociedade, o termo 'intercultural" significa a interação entre as diferentes culturas" (Barbosa, 1998:14).

Vimos no primeiro capítulo que um espaço multicultural nasce e se desenvolve nesse imenso laboratório que é a sociedade. Andrea Semprini (1999) destaca que o espaço multicultural é antes de tudo um espaço de sentido, uma semiosfera onde a circulação dos símbolos é pelo menos tão importante quanto a circulação dos bens e outros benefícios materiais. Vimos também que a questão primordial da multiculturalidade é a diferença. Daí surgem problemas identitários e de pertencimento. A questão da identidade cultural de um país está comprometida com o multiculturalismo - pois não é única, fixa.

O multiculturalismo é com freqüência acusado de comprometer a unidade social e política, de comprometer, ou mesmo subverter, a dinâmica da integração, de levar indivíduos a se fechar no interior de seu grupo étnico, religioso, racial, sexual, cultural - de pertença (Semprini, 1999:129).

Percebemos que o Brasil é um país multicultural por formação e que aqui existem diversos povos e culturas convivendo e trocando informações. Porém, não basta apenas adicionar à cultura dominante elementos de outras culturas, o chamado multiculturalismo aditivo (Barbosa, 1998). É mais importante promover a relação e a interação entre essas diferentes culturas, centrais e periféricas - promover e estimular a interculturalidade.

Hoje, os processos globalizadores acentuam as relações entre culturas, pois criam mercados mundiais e diminuem as fronteiras entre países, aumentando as interações. Assim também ocorre com as tradições locais, que são transformadas ao 
interagirem com o universo cultural global. Todo esse processo aproxima do que podemos chamar de Hibridismo.

\subsection{DESIGN HÍBRIDO}

Quando o design passa a trocar informações com outras áreas, possíveis alterações nos significados da produção material acontecem, por meio de um processo chamado hibridização. Entende-se por hibridização, ou hibridismos, os "processos socioculturais nos quais estruturas ou práticas discretas, que existiam de forma separada, se combinam para gerar novas estruturas, objetos e práticas" (Canclini, 2006: XIX). Sendo assim, observamos que o design, ao trocar informações e técnicas com as artes populares, incluindo o artesanato, passa por um processo de hibridização, gerando novas estruturas, antes não pensadas.

Havia anteriormente, de acordo com Canclini (2006), uma idéia de que os bens tradicionais seriam apagados pela industrialização: os mitos seriam substituídos pelo conhecimento científico, o artesanato pela expansão da indústria, os livros pelos meios audiovisuais de comunicação.

A idéia do hibridismo nos ajuda a pensar que esses bens passaram a ser incorporados a outras práticas e, desta forma, não desapareceram. É através desses processos de trocas culturais que podemos obter uma visão mais complexa sobre as relações entre a tradição e a contemporaneidade.

Esse é um caminho a ser seguido por diversas áreas, a exemplo do design, que vê no artesanato a possibilidade de unir técnica e conhecimento, e assim produzir artefatos repletos de elementos culturais e simbólicos - elementos que os bens industriais nem sempre oferecem. Se pensarmos também pelo lado popular, da arte e do artesanato, esse processo de trocas é também valioso, pois seus produtos mantém as funções tradicionais e desenvolvem outras, mais modernas. Dessa forma, as artes manuais e tradicionais são apenas transformadas, e não extintas, como poderia acontecer com o boom dos produtos industrializados.

Os híbridos, na biologia, são o resultado da "mistura de espécies diferentes" (Feitosa, 2006:113). Essa fusão de dois seres diferentes não resulta em um terceiro ser, heterogêneo, mas sim em um ser caracterizado por diferenças e ambigüidades. 0 mesmo acontece ao transferirmos o termo para a cultura, quando todos os povos e culturas diferentes se misturam, formando um mosaico que produz, no final, uma cultura própria, formada por todos esses elementos, como disse Amálio Pinheiro. Assim é a cultura múltipla brasileira, um mosaico, a cultura híbrida.

A hibridação não é sinônimo de fusão sem contradições, mas, sim, que pode ajudar a dar conta de formas particulares de conflito geradas na interculturalidade recente em meio à decadência de projetos nacionais de modernização na América Latina.

Essa passagem do termo hibridismo da biologia para os estudos socioculturais ganhou diversas aplicações e talvez tenha ficado muito abrangente para aqueles teóricos que preferem usar termos já existentes e mais específicos ao caracterizar as combinações: como "sincretismo", para as misturas religiosas; e "mestiçagem", para a mistura entre povos. 
No entanto, a flexibilidade da palavra hibridismo permite não só nomear essas combinações já características, como também diversas outras misturas e processos sociais modernos e pós-modernos, como descreve Canclini:

O conceito de hibridação é útil em algumas pesquisas para abranger conjuntamente contatos interculturais que costumam receber nomes diferentes: as fusões raciais ou étnicas denominadas mestiçagem. O sincretismo de crenças e também outras misturas modernas entre o artesanal e o industrial, o culto e o popular, o escrito e o visual nas mensagens midiáticas (Canclini, 2006: XXVII).

Essa mistura entre o artesanal e o industrial descrita por Canclini e o objeto que essa relação produz pode ser denominado design híbrido:

O design híbrido, além de relacionar diversas linguagens, procedimentos e mídias, caminha no sentido de atingir todos os sentidos humanos e integrar diferentes campos de saber, rompendo com a distancia e os muros existentes entre estas áreas. Arquitetura, engenharia, moda, música, urbanismo se integram e se somam, rompendo com valores e padrões há muito estabelecidos e constituindo o design híbrido, próprio da contemporaneidade (Moura, 2005:8).

Percebemos que, através dessa forma de integração, o design passa a conter elementos evidenciadores da diversidade. O design híbrido pode se aproximar de inovações tecnológicas sofisticadas, mas também pode incorporar técnicas e tradições produtivas artesanais. Práticas já trabalhadas e discutidas dentro do campo do design. A interculturalidade passa a ser evidenciada através desses encontros, como aponta Canclini (2006:XXVII),

A hibridação, como processo de interseção e transações, é o que torna possível que a multiculturalidade evite o que tem de segregação e se converta em interculturalidade. Podemos escolher viver em estado de guerra, ou em estado de hibridação.

A hibridação é uma fusão que traz muitos benefícios para a cultura e seus diversos segmentos, mas não podermos nos esquecer de que sempre vão existir divergências, e de que todo encontro entre culturas específicas e diferentes pode provocar também diversos conflitos. Existem ganhos e perdas nesse processo de hibridação, mas é cada vez mais necessário que consigamos conviver em meios às diferenças existentes no mundo.

\section{CONCLUSÃO}

Nessa nova fase da globalização, chamada de "segunda modernidade" por pensadores como Ulrich Beck, passamos a ser mais reflexivos e aceitamos melhor as diversas tradições, a pluralidade do mundo. Essa nova etapa da globalização é vista aqui como refletida no design, que busca incorporar às suas tecnologias e processos a tradução de nossa cultura material. Modernidade e tradição se unem e se transformam em artefatos repletos de novos sentidos e conceitos, valorizando nossa cultura local e caminhando em direção a referências próprias, mas trazendo também influências globais. 
Assim, local e global se misturam em uma estética do design mais próxima de nossa cultura. $O$ design passa a considerar a cultura e o território como valores, e dessa forma passa da esfera funcional para outras: cultural, intelectual, social.

Este artigo é uma reflexão sobre algumas das questões que envolvem o design hoje no Brasil. Entender as relações e os caminhos encontrados pelo design contemporâneo é uma forma de compreender como existem diversas possibilidades projetuais, além daquelas inicialmente conhecidas pelo design. Questões culturais e sociais estão cada vez mais presentes nestes contatos e o design no Brasil está repleto de novas e boas possibilidades de crescimento. Percebemos o design em constante renovação, mais livre e mais expressivo, dentro deste novo cenário mundial. O design busca hoje encontrar suas singularidades, renovando-se esteticamente e trazendo elementos da cultura do país através de suas relações com outros elementos.

Os produtos gerados por essas relações nos mostram quem somos e de que maneira podemos ter reconhecimento global, através de nossas produções locais.

O trabalho dos irmãos Campana, de designers como Maurício Azeredo, Renato Imbroisi, Zanini e Fabíola Bergamo, e de estilistas como Lino Villaventura e Ronaldo Fraga, são exemplos claros dessas relações e desta estética cultural do design brasileiro - reconhecidas não só no país, como em outras partes do mundo.

O design, desta forma, busca condições favoráveis para seu crescimento cultural, social e estético, reforçando sua importância na formação da cultura material do país e mostrando que existe, sim, uma maneira de traçar um caminho próprio.

$O$ design traz toda a sua bagagem global, projetual e tecnológica, mas assimila um outro lado, o da tradição, das técnicas manuais, da cultura e desta forma, busca condições favoráveis para seu crescimento cultural, social e estético, reforçando sua importância na formação da cultura material do país e mostrando que existe, sim, uma maneira de traçar um caminho próprio.

\section{REFERÊNCIAS}

ANJOS, Moacir dos. Local/global: arte em trânsito. Rio de Janeiro: Jorge Zahar Ed., 2005.

BHABHA, H. K. O local da cultura. Trad. Myriam Ávila et al. Belo Horizonte, Ed. UFMG, 1998.

BARBOSA, Ana Mae. Tópicos Utópicos. Belo Horizonte: C/Arte, 1998.

BURKE, Peter. Hibridismo Cultural. Rio Grande do Sul: Ed. Unisinos, 2003. CARDOSO,

Rafael. Uma Introdução à História do Design. São Paulo, Edgard Blücher, 2004. . "Design, cultural material e fetichismo dos objetos". In: LEITE, J. S. et al

(ed.). Arcos: design,cultura material e visualidade. Rio de Janeiro: Contra Capa, 1998.

CANCLINI, Nestor Garcia. Culturas Híbridas: Estratégias para Entrar e Sair da

Modernidade. 4. ed 1. reimp. - São Paulo: EDUSP, 2006.

Consumidores e Cidadãos: conflitos multiculturais da globalização. Rio de 
Janeiro: Editora UFRJ, 1999.

CHARTIER, R. A História Cultural. Entre Práticas e Representações. Lisboa: Difel, 1987. CIPINIUK, A; PORTINARI, D e BOMFIM, G. "Cultura”, in: COELHO, Luiz A. L. (org.). Conceitos-chave em design. Rio de Janeiro: Puc-Rio, Novas Idéias, 2008.

COELHO, Luiz A. L. (org.). Conceitos-chave em design. Rio de Janeiro: Puc- Rio, Novas Idéias, 2008.

FEITOSA, Charles. As Formas Híbridas. In: Revista Bravo!, No 104, Abril 2006

GEERTZ, Clifford. A interpretação das culturas. Rio de Janeiro: Ed. ITC, 1989.

HALL, Stuart. A identidade cultural na pós-modernidade. Rio de Janeiro: DP\&A, 2005. MOURA, Mônica. Design Contemporâneo = Cultura Digital + Linguagem + Hibridismo, in: Anais 30 Congresso Internacional de Pesquisa em Design Brasil, Rio de Janeiro, 2005.

ONO, Maristela. Design e Cultura: sintonia essencial. Curitiba: Edição da Autora, 2006. 100

ORTIZ, Renato. Cultura Brasileira e identidade nacional. São Paulo: Ed. Brasiliense, 1985.

SEMPRINI, Andrea. Multiculturalismo. Bauru, SP: EDUSC, 1999.

SILVA, Tomaz Tadeu da. Identidade e Diferença: a perspectiva dos estudos culturais. Tomaz Tadeu da Silva (org). Stuart Hall, Kathryn Woodward. Petrópolis, RJ: Vozes, 2000.

VILLAS-BOAS, André. Identidade e Cultura. Rio de Janeiro: 2AB Ed., 2002. 